\title{
O LEGADO DE ALIMENTOS EM FAVOR DAS PESSOAS NÃO LEGITIMADAS A SUCEDER POR TESTAMENTO
}

\section{THE LEGACY OF MAINTENANCE CLAIM IN FAVOR OF PEOPLE NOT LEGITIMATE TO SUCCEED BY LAST WILL AND TESTAMENT}

\author{
${ }^{1}$ Raphael Rego Borges Ribeiro
}

\section{RESUMO}

A lei retira a legitimação sucessória de algumas pessoas, em razão de circunstâncias excepcionais, no intuito de proteger a idoneidade do testamento. Assim, a princípio, qualquer disposição em favor de tais pessoas é nula de pleno direito. Entretanto, o presente trabalho questiona se tal nulidade deve ser aplicada também ao legado de alimentos. Destaca-se a natureza eminentemente assistencial do instituto, bem como a importância da obrigação alimentar para a concretização do direito à vida digna.

Palavras-chave: Legado, Alimentos, Legitimação, Sucessão

\section{ABSTRACT}

The law removes the succession legitimacy of some people, because of exceptional circumstances, in order to protect the idoneity of the will. Thus, in principle, any devise in favor of such people is null and void. However, this paper questions whether such nullity shall be applied also to the legacy of maintenance claim. Stands out the eminently supportive nature of the institute as well as the importance of the maintenance obligation for the realization of the right to a dignified life.

Keywords/Palabras-claves/Mots-clés: Legacy, Maintenance claim, Legitimacy, Succession

\footnotetext{
${ }^{1}$ Mestre em Direito pela Universidade Federal da Bahia, UFBA, Salvador, BA. Professor na Universidade Federal da Bahia- UFBA, Salvador BA, (Brasil). E-mail: raphaelregobr@gmail.com
} 


\section{INTRODUÇÃO}

O presente trabalho defende que a sanção de invalidade prevista no artigo 1.802 do Código Civil de 2002 não se aplica ipso jure à hipótese do legado de alimentos instituído em favor de pessoa não legitimada a suceder.

Para sustentar tal hipótese, inicialmente será realizada uma breve análise a respeito do legado de alimentos. Buscar-se-á compreender a natureza jurídica da obrigação alimentar, de forma a evidenciar seu caráter eminentemente assistencial. Será ressaltado, assim, que tal instituto não constitui fonte de enriquecimento, mas em realidade é um verdadeiro mecanismo assegurador do direito à vida e à dignidade do alimentando - in casu, do legatário.

Na sequência, serão estudadas as hipóteses de falta de legitimação para suceder. A pesquisa se debruçará sobre os fundamentos jurídicos destas circunstâncias excepcionais, nas quais o legislador compreende que determinadas pessoas não podem ser beneficiadas por um específico testamento. Nesta mesma oportunidade, ficará evidenciada a sanção jurídica que opera de pleno direito sobre disposições testamentárias em favor de tais indivíduos.

Por fim, será questionado se uma regra proibitória estabelecida pelo Código Civil pode obstar a efetividade do exercício dos direitos fundamentais acima mencionados. Por outro lado, é possível estabelecer exceções aos impedimentos sucessórios, mesmo havendo silêncio da lei a este respeito?

Trata-se de questão cuja resposta deve levar em consideração a tendência de constitucionalização do Direito Civil, cujos efeitos se sentem inclusive no campo do Direito das Sucessões. Com efeito, a lei sucessória também deve tomar a pessoa humana como alvo central de sua tutela e proteção.

\section{O LEGADO DE ALIMENTOS}

Antes de iniciar a análise da possibilidade de serem legados alimentos a uma pessoa não legitimada a suceder, imprescindível se faz compreender o conteúdo de tal disposição testamentária. Para tanto, é necessário estabelecer as bases conceituais do instituto, especialmente definindo de forma técnica os seus elementos. 
Em primeiro lugar, serão tecidas algumas considerações a respeito dos legados em geral. Na sequência, será feita uma análise acerca das principais características da obrigação alimentar. Após as devidas ponderações, tornar-se-á possível uma melhor compreensão sobre o legado de alimentos propriamente dito.

\subsection{O LEGADO}

O legado é um instituto do Direito das Sucessões. Este é o ramo do direito que estuda a sucessão em sentido estrito ou causa mortis, ou seja, a mudança subjetiva verificada em determinadas relações jurídicas que, mesmo após o óbito de um dos seus titulares, permanecem no universo jurídico.

No direito sucessório "há o prefalecido e o sobrevivente, ou os sobreviventes, que recolhem a herança, senso lato" (PONTES DE MIRANDA, 1968, v.LV, p.05). Percebe-se, assim, a existência de duas posições jurídicas: a do sucedido, ou seja, do morto; e a do sucessor, que é a pessoa a quem são transmitidos os direitos e as obrigações anteriormente titularizados por quem morreu.

A sucessão causa mortis pode se dar a título universal ou a título singular. Neste ponto, reside a essencial diferenciação entre a herança e o legado.

Na sucessão a título universal há a transmissão da totalidade do patrimônio do falecido ou de parte ideal (fração ou alíquota) dele. Em tal hipótese, o sucessor, que será denominado herdeiro, recolherá a herança. Trata-se de modalidade sucessória que pode ocorrer tanto por força de lei quanto por força de testamento.

Por outro lado, na sucessão a título singular o falecido deixa um bem determinado ou ao menos determinável - e certo, chamado legado, para o sucessor, que recebe a designação de legatário. No direito brasileiro atual só é possível a existência de legados na sucessão testamentária.

Em relação à distinção entre as sucessões a título universal e singular, é importante destacar que pouco importa o nome eventualmente utilizado pelo testador na cláusula testamentária. Se há disposição de parte ideal do seu patrimônio, invariavelmente ele estará instituindo herdeiro, ainda que no testamento conste outra nomenclatura. Por outro lado, se 
fez uma liberalidade consistente em um bem determinado e certo, necessariamente fez surgir um legado.

\subsubsection{O OBJETO DO LEGADO}

Conforme já destacado anteriormente, não há legado fora da sucessão testamentária. Disto se depreende que constará no testamento tanto a designação do legatário quanto a indicação do bem ou da prestação que consistirá no objeto do legado.

O testamento é negócio jurídico gratuito, essencialmente revogável, unilateral, personalíssimo e solene, cujos efeitos são produzidos apenas após a morte do disponente. Nesse sentido, a lei confere a autonomia privada ao testador, que poderá dispor livremente dos seus bens para depois da sua morte, desde que sejam respeitados alguns limites de ordem pública.

Dessa forma, a liberdade de testar é restringida pelas regras de capacidade testamentária ativa e passiva (tema que será aprofundado em momento posterior); pela intangibilidade da legítima dos herdeiros necessários; pelas solenidades específicas exigidas para as formas testamentárias prescritas em lei; e pelas regras de validade dos negócios jurídicos previstas na Parte Geral do Código Civil.

Pelo exposto, o objeto do legado deve ser lícito, possível e determinado ou, ao menos, determinável. Respeitados tais requisitos, é ampla a liberdade de disposição do testador.

Assim, de forma exemplificativa, poderá ser objeto do legado um bem móvel ou imóvel; um crédito; a quitação de uma dívida; o direito de usufruto; uma soma em dinheiro; prestações periódicas; coisa incerta, a ser determinada pelo gênero ou pela espécie; e, finalmente, a prestação de alimentos.

\subsection{OS ALIMENTOS}

Numa conceituação leiga, a palavra "alimento" pode ser interpretada de forma restrita ao que é comestível, à comida de forma geral. Entretanto, para o Direito, o mesmo vocábulo tem significado bem mais amplo, correspondendo a um dos institutos de maior importância para garantir a eficácia social do princípio da dignidade da pessoa humana. 
Com efeito, os "alimentos são prestações para satisfação das necessidades vitais de quem não pode provê-las por si” (GOMES, 1987, p.404). Na medida em que a pessoa não pode garantir, por si mesma, a sua subsistência digna, recorre ao amparo de quem pode contribuir para auxiliar no seu sustento.

Do próprio conceito da obrigação alimentar, depreende-se que "o dever de prestar alimentos funda-se na solidariedade humana e econômica" (GONÇALVES, 2012, p.499) que deve existir entre pessoas que guardam determinados vínculos jurídicos entre si.

Os referidos vínculos jurídicos ensejadores de obrigação alimentar entre determinadas pessoas são, basicamente, a lei, uma declaração de vontade ou mesmo um ato ilícito.

Quando são devidos em virtude da lei, os alimentos são chamados legítimos e podem decorrer do parentesco, do casamento ou da união estável. Já a obrigação alimentar cuja origem é o ato ilícito tem natureza indenizatória ou ressarcitória de algum dano. Por fim, os alimentos que surgem de uma manifestação de vontade são denominados voluntários e podem advir de ato inter vivos ou causa mortis.

Independentemente da causa jurídica dos alimentos, em cada caso concreto, a sua finalidade "é assegurar o direito à vida" (WALD, 1991, p.43) De fato, trata-se de um instrumento jurídico que objetiva assegurar a manutenção deste direito fundamental, valendo destacar, no particular, que não se trata apenas da sobrevivência do alimentado, mas também da garantia de manutenção, pelo menos, dos padrões qualitativos mínimos para a sua existência.

É crucial destacar o "acentuado caráter assistencial” (GONÇALVES, 2012, p.500) do instituto. De modo geral, como já foi mencionado (se mencionou), a obrigação alimentar assegura as condições de sustento de quem, por si mesmo, não tem os meios para assegurar a própria subsistência. Isso significa que, se não os recebe de quem deve prestá-los, a pessoa que necessita de alimentos provavelmente passará por momentos de privação das condições mínimas que asseguram uma existência humana com dignidade.

Nesse sentido, é possível afirmar que a obrigação alimentar é uma aplicação dos direitos sociais, previstos no artigo $6^{\circ}$ da Constituição Federal de 1988, às relações de Direito Privado. Afinal, trata-se de meio previsto pelo Estado de assegurar a assistência aos 
desamparados, prestada por particular que tem vínculo jurídico com o assistido, conforme já exposto.

O cumprimento das normas que preveem e regulamentam os alimentos interessa diretamente ao Estado, isto porque, quando envolve alimentos, a sua inobservância "aumenta o número de pessoas carentes e desprotegidas, que devem, em consequência, ser por ele amparadas" (GONÇALVES, 2012, p.499).

Percebe-se uma evidente orientação do ordenamento jurídico brasileiro para a garantia da efetividade do cumprimento da obrigação alimentar. O maior exemplo disto é que a prisão civil por dívida só é permitida na hipótese de inadimplemento voluntário e inescusável dos alimentos legais.

Conclui-se, portanto, que a natureza jurídica dos alimentos - sejam eles legais, voluntários ou indenizatórios - exige que o intérprete do Direito aplique as normas pertinentes ao instituto sempre de forma a garantir a efetividade das prestações e amparo ao alimentando.

\subsection{O LEGADO DE ALIMENTOS}

O legado de alimentos é uma modalidade de obrigação alimentar resultante de manifestação de vontade, especificamente mediante ato causa mortis, qual seja, o testamento. Com efeito, "por disposição testamentária pode-se instituir, em favor de legatário, o direito a alimentos, enquanto viver" (GOMES, 1987, p.404).

O legislador brasileiro se preocupou em estabelecer, no artigo 1.920 do Código Civil, que "o legado de alimentos abrange o sustento, a cura, o vestuário e a casa, enquanto o legatário viver, além da educação, se ele for menor”. Depreende-se, do texto citado, que tal disposição testamentária não se limita ao indispensável ao sustento do legatário, mas também compreende "o necessário à manutenção da condição social e moral do alimentando" (GONÇALVES, 2013, p.370).

É necessário esclarecer que, na verdade, por se tratar de instituição voluntária da obrigação alimentar, incumbe primordialmente ao autor do testamento estabelecer as disposições que regularão os alimentos iure testamenti, como o valor das prestações ou o período durante o qual elas deverão ser pagas (NONATO, 1957, v.III, p.68). Dessa forma, de acordo com Pontes de Miranda (1969, v.LVII, p.203), "se o testador determinou o quanto da 
prestação mensal, ou semanal, ou de outra prestação periódica, não pode o juiz diminui-la, nem aumenta-la, mesmo que haja deficiência ou excessividade".

Assim, apenas na hipótese de o testador não ter estabelecido o montante do legado de alimentos, caberá ao juiz tal fixação, levando em consideração os critérios previstos no já mencionado dispositivo do Código Civil. Obviamente, o magistrado deverá estabelecer a expressão pecuniária da obrigação alimentar levando igualmente em conta as forças da herança, as necessidades do legatário e a sua condição para com o falecido (MAXIMILIANO, 1964, p.352).

Orosimbo Nonato (1957, v.III, p.68) ensina que, quando a lei inclui as despesas com educação no cálculo da extensão do legado de alimentos, nestes estarão abrangidos os "pagamentos de colégios, livros, mestres, material de ensino, matrículas", bem como todos os outros gastos essenciais à qualificação acadêmica e profissional. Apesar de o Código Civil vincular tal parcela da obrigação alimentar especificamente ao período durante o qual o legatário é menor de idade, a jurisprudência pátria é pacífica no sentido de estendê-la pelo menos até a conclusão de curso de ensino superior.

Ainda de acordo com o magistério de Orosimbo Nonato (1957, v.III, p.67-68), “o sustento alcança todo o necessário a nutrir e conservar o corpo, alimentos propriamente ditos", ou seja, o legado de alimentos deve assegurar ao legatário as condições para a sua subsistência física. Por outro lado, “a cura compreende as despesas todas da medicação: pagamento aos profissionais, cuidados hospitalares e de enfermagem, remédios, assistência, etc", enquanto o vestuário alcança aquilo "que serve a livrar da nudez e a guardar uma exterioridade conveniente e decorosa".

A partir do momento em que o montante do legado é fixado pelo de cujus ou pelo juiz, tal valor "é inalterável pela mudança das circunstâncias e da situação econômica ou sanitária do beneficiado, salvo se o testador estabeleceu critérios para alterações, ou se os alimentos são renda de bem ou de bens" (PONTES DE MIRANDA, 1969, v.LVII, p.203). Verifica-se, neste ponto, uma distinção em relação à obrigação alimentar determinada por força de lei, cuja extensão pode ser majorada ou minorada de acordo com alteração das condições do alimentante ou do alimentando.

Por outro lado, se o de cujus não consignou no testamento até quando devem ser prestados os alimentos, entende-se que eles são vitalícios, exceto as parcelas do legado 
referentes ao cumprimento do dever de educação, que são devidas apenas durante o tempo necessário para a instrução do beneficiado (GONÇALVES, 2013, p.370).

Pontes de Miranda (1969, v.LVII, p.203) sustenta que o legado de alimentos pode ser pago a partir da renda de um determinado bem da herança, se assim tiver determinado o de cujus. É possível que uma fração do monte hereditário seja separada com o propósito de assegurar o cumprimento da obrigação alimentar. Alternativamente, o testador pode estabelecer que determinado herdeiro tenha seu quinhão onerado com o pagamento dos alimentos. Neste sentido, o testamento pode consignar o pagamento do legado como um encargo ou como uma condição da instituição de algum herdeiro ou de outro legatário.

Uma vez aceito o legado de alimentos, a obrigação alimentar se torna devida desde o falecimento do de cujus. A natureza de tal obrigação alimentar exige que o seu adimplemento se inicie assim que possível, a despeito de, em geral, os legados serem pagos após a partilha. Como se destinam à sobrevivência do legatário, nada justifica que tal pagamento aguarde a ultimação do inventário (DIAS, 2013, p. 418).

O legado de alimentos é disposição testamentária motivada pela caridade e pela solidariedade do testador para com o legatário. Destina-se a assegurar ao beneficiário pelo menos um pouco de uma boa qualidade de vida, permitindo-lhe o acesso a bens materiais e a oportunidades que, provavelmente, não conseguiria alcançar por intermédio das suas próprias forças.

Em razão da sua natureza e das suas finalidades, o legado de alimentos é impenhorável, inarrestável e insequestrável. Da mesma forma, “o herdeiro, que há de cumprir a disposição testamentária, não pode reter prestações, nem alegar compensação, com a afirmativa de ser credor do legatário" (PONTES DE MIRANDA, 1969, v.LVII, p.204). Além disso, as normas pertinentes ao instituto deverão ser aplicadas de forma a garantir o amparo ao beneficiário.

\section{AS PESSOAS NÃO LEGITIMADAS A SUCEDER}

Conforme já exposto, o Direito das Sucessões estuda e regula a transmissão do patrimônio, lato sensu, de alguém que faleceu para os seus sucessores. Não é qualquer um que pode invocar para si o título de herdeiro ou legatário. A lei estabelece pressupostos para que 
determinada pessoa seja chamada à sucessão: trata-se da capacidade sucessória - ou legitimação para suceder, como prefere a doutrina mais moderna.

Caio Mário ensina que capacidade sucessória é a "aptidão da pessoa para receber os bens deixados pelo falecido" (2013, p.24). Este autor segue lecionando que os mencionados pressupostos de sucessibilidade "se resumem nestas duas circunstâncias: a existência para fins de sucessão e a sua convocação para receber por causa de morte".

Em se tratando do primeiro pressuposto de capacidade sucessória, a existência, o artigo 1.798 Código Civil de 2002 estabelece que são legitimadas a suceder as pessoas já nascidas ou pelo menos já concebidas no momento da abertura da sucessão. Entretanto, o legislador permite que tal regra seja excepcionada através do benefício testamentário a pessoa ainda não concebida no instante do óbito do de cujus.

O segundo pressuposto de legitimação para suceder é a vocação sucessória. Para que uma pessoa seja sucessora de outra é imprescindível que haja o seu chamamento à sucessão, que ocorre através de um título jurídico. De acordo com as lições de Lacerda de Almeida (1915, p.58), este título poderá ser a vontade do defunto, solenemente manifestada em testamento - tratando-se, então, de vocação testamentária; ou a lei, que supre ou mesmo restringe a vontade do falecido, caso em que o chamamento será legítimo.

A vocação sucessória testamentária tem características peculiares em relação à legítima. Nesse sentido, já se mencionou que o testador pode inclusive excepcionar o primeiro pressuposto de sucessibilidade, chamando à sua sucessão pessoa que ainda sequer foi concebida no instante de sua morte.

Por outro lado, a autonomia privada do testador é limitada pelo ordenamento jurídico, pois este proíbe que o disponente nomeie determinadas pessoas como seus legatários ou herdeiros: são casos de impedimentos sucessórios, que somente podem ser instituídos por lei e devem respeitar os princípios constitucionais aplicáveis à hipótese (PONTES DE MIRANDA, 1969, v.LVIII, p.03).

Dessa forma, Itabaiana de Oliveira (1936, p.34) sustenta que, sempre que se faça necessário executar uma disposição testamentária, é imprescindível verificar, em primeiro lugar, se as pessoas nela beneficiadas têm a capacidade exigida pela lei para que o benefício testamentário lhes aproveite. 
Em um momento mais antigo, a doutrina do Direito das Sucessões dividia as incapacidades testamentárias passivas em absolutas e relativas. No primeiro caso, o impedimento era de receber por força de todo e qualquer testamento, fosse de quem fosse; tratava-se de situação relacionada com o primeiro pressuposto de sucessibilidade, qual seja, a existência para fins hereditários. A segunda hipótese se referia apenas à impossibilidade de alguém ser chamado pela via testamentária a uma específica e "determinada sucessão, de partilhar do espólio de certas pessoas ou de haver certos bens" (MAXIMILIANO, 1964, p. 489).

Sobre esta divisão, Guilherme Calmon Nogueira da Gama (2007, p.227) ensina que:

contemporaneamente, tal classificação perdeu sua utilidade, especialmente em decorrência da evolução da ciência do direito, com a distinção entre incapacidade e ilegitimidade (ou falta de legitimação). A incapacidade é geral, não permitindo que haja qualquer benefício sucessório por testamento, ao passo que a ilegitimidade é circunstancial, aplicando-se apenas em relação a determinada pessoa, com base em fundamento considerado relevante para criar tal óbice ou restrição legal.

Portanto, verifica-se que os impedimentos legais que proíbem a disposição testamentária em favor de determinadas pessoas emergem de normas relacionadas à falta de legitimação para suceder. Tais pessoas podem ser chamadas, na qualidade de como herdeiras instituídas ou legatárias, em qualquer sucessão, exceto naquela em que há a incidência dessas circunstâncias consideradas graves pelo ordenamento jurídico.

No direito brasileiro atual, as pessoas não legitimadas para receber por testamento, na condição de herdeiras ou de legatárias são: a que escreveu o testamento a rogo do disponente, bem como o seu cônjuge, companheiro, ascendentes e irmãos; as testemunhas do testamento; o concubino do testador casado, ressalvada hipótese específica de separação de fato; e o tabelião, civil ou militar, ou o comandante ou escrivão, perante quem se fizer ou que fizer ou aprovar o ato de disposição.

A lei proíbe a instituição de tais pessoas na condição de herdeiras ou legatárias em um determinado testamento porque as considera suspeitas naquela conjuntura.

Carlos Roberto Gonçalves (2013, p.81) aduz que, no caso específico do concubino do testador casado, a vedação "complementa a série de dispositivos destinados a proteger a família legítima e a coibir o adultério". Seguindo linha de pensamento semelhante, Orosimbo Nonato (1957, v.II, p.58) defende que tal impedimento existe em "defesa dos bons costumes e de respeitáveis interesses da família”. 
O Código Civil abre uma exceção à mencionada regra, permitindo que o testador casado beneficie o seu concubino se estiver separado de fato do cônjuge há mais de cinco anos, sem culpa sua. Tal dispositivo tem o mérito de reconhecer a dissolução da sociedade conjugal pela separação, afastando o impedimento sucessório. Contudo, trata-se de norma muito criticada, pois o prazo estabelecido é considerado excessivo; ademais, reacende desnecessariamente o debate a respeito de culpabilidade na separação, o que contraria a tendência atual do Direito de Família.

Nas demais situações, as proibições visam a segurança e a livre manifestação de vontade do disponente, "objetivando evitar que tais pessoas se vejam tentadas a abusar da confiança nelas depositada e procurem alterar a vontade do testador para obter algum benefício para si ou seus parentes, ou, ainda, para o cônjuge ou companheiro" (GONÇALVES, 2013, p.80). Com efeito, as pessoas ali elencadas podem forjar disposições testamentárias, "alterando ou induzindo a vontade do testador" (DIAS, 2013, p.348).

Em relação à pessoa que escreve o testamento a rogo do disponente, o impedimento existe para evitar que, se desprovido de escrúpulos e honestidade, tal sujeito opte por "escrever propositadamente errado e introduzir disposições ou suscitar-lhes modificações em seu prol ou no de seus propínquos indicados na lei" (NONATO, 1957, v.II, p.48). Silvio Rodrigues (1999, p.175) sugere que a proibição obsta a cobiça e a tentação do redator.

Da mesma forma, a lei impossibilita que as testemunhas de um testamento sejam nele beneficiadas, na medida em que, participando da própria feitura do negócio jurídico, devem ser isentas de qualquer interesse material no caso (NONATO, v.II, p.52). Igualmente, Itabaiana de Oliveira (1936, p.38) defende que "a verdade e a segurança das disposições testamentárias melhor se asseguram pelo testemunho daqueles que não foram contemplados no testamento, porque eles nenhum interesse têm nas liberalidades feitas pelo testador".

Por fim, os argumentos acima expostos podem ser aplicados perfeitamente para fundamentar a falta de legitimação sucessória do escrivão, do tabelião ou do comandante que fizer, aprovar ou perante quem se fizer o ato de disposição.

Os mencionados impedimentos subsistem ainda que o benefício testamentário venha simulado sob a forma de contrato oneroso. Trata-se de situação fraudulenta, na qual o testador, por exemplo, confessa ser devedor da pessoa não legitimada para sucedê-lo. Vale 
destacar que o negócio jurídico simulado é nulo, de acordo com a previsão da Parte Geral do Código Civil.

Da mesma forma, o ordenamento jurídico proíbe a hipótese de alguém não legitimado a suceder possa ser favorecido por testamento de forma oblíqua, mediante interposta pessoa. Tal situação ocorre "quando a deixa testamentária beneficia diretamente um terceiro e indiretamente o incapaz" (RODRIGUES, 1999, p. 179).

Nesse sentido, de forma a preservar a eficácia do impedimento sucessório, a lei presume que são pessoas interpostas os ascendentes, os descendentes, os irmãos e o cônjuge ou companheiro do não legitimado a suceder. Dessa forma, também não poderá ser feita disposição testamentária em favor desses indivíduos.

De modo geral, a doutrina reconhece que, em relação a tais pessoas, há presunção absoluta de interposição que favorece o não legitimado. Todavia, uma interpretação muito severa desta norma pode levar a exageros e injustiças (NONATO, 1957 v.II, p.68). Por essa razão, e levando em consideração o tratamento isonômico que deve ser garantido a toda a prole, o Supremo Tribunal Federal editou a sua Súmula 447, na qual considera válida a disposição em favor do filho do testador com a sua concubina.

Por outro lado, nada impede que haja tentativa de burla ao impedimento sucessório, a partir da disposição em favor de outrem que não conste na mencionada lista de presunções absolutas. Nestas situações, obviamente, os sucessores interessados poderão fazer prova de que há infração ao comando legal.

De todo modo, havendo benefício testamentário direto ou indireto a pessoa não legitimada a suceder, a mencionada disposição será nula e, portanto, não produzirá qualquer efeito. Não há nulidade de todo o testamento, mas apenas da parte em que há desrespeito ao impedimento legal. Carlos Maximiliano (1964, p.526) afirma que, por se tratar de matéria de ordem pública, a invalidade advém de pleno direito, ainda que contrariamente à vontade do testador.

Importa reiterar que, ao estabelecer impedimentos sucessórios, a lei deve estar em conformidade com os princípios constitucionais explícitos e implícitos. Justamente por essa razão há a exceção estabelecida pela Súmula 447 do STF. Assim, também as regras de legitimação para receber por testamento devem ser orientadas tendo a pessoa humana como alvo central da tutela e da proteção do ordenamento jurídico (GAMA, 2007, p.193). 


\section{A INSTITUIÇÃO DE LEGAdO DE ALIMENTOS EM FAVOR DE PESSOAS NÃO LEGITIMADAS A SUCEDER}

Até este momento, foram analisados os aspectos pertinentes ao instituto dos legados, especificamente a disposição testamentária que estabelece obrigação alimentar em favor de um legatário. Por outro lado, foram expostas as hipóteses em que a lei proíbe que determinadas pessoas sejam beneficiadas em testamento como sucessoras a título universal ou singular.

Quando se analisam isoladamente as normas a respeito dos impedimentos sucessórios, conclui-se que basicamente qualquer deixa testamentária que os infrinja é eivada de nulidade, por expressa determinação legal. A consequência desta interpretação é que não seria válida a cláusula do testamento através da qual alguém institui um legado de alimentos em favor de pessoa não legitimada a sucedê-lo.

Neste sentido, Carlos Roberto Gonçalves (2013, p.371) entende que "as referidas pessoas não têm legitimidade para usufruir de qualquer disposição testamentária”. Por seu turno, Maria Berenice Dias (2013, p.148) defende que só pode beneficiado com o legado de alimentos o indivíduo a quem o ordenamento confere legitimação sucessória; assim, "não há como excepcionar o que a lei não excepciona", ainda que sob o argumento do caráter de subsistência do direito à vida.

Com todas as vênias aos mencionados doutrinadores, não é possível partilhar da conclusão a que eles chegam. A discordância em relação aos aludidos entendimentos deriva de uma investigação baseada na moderna orientação do Direito das Sucessões, que cada vez mais sofre uma influência decisiva dos princípios constitucionais.

A este respeito, deve-se considerar que o Direito Civil, como um todo, "não pode mais ser analisado sob a ótica individualista, patrimonialista, tradicional e conservadoraelitista" (GAMA, 2007, p.192) que prevalecia no período anterior à Constituição Federal de 1988 e, mais especificamente, na vigência do Código Civil de 1916.

As transformações sociais, culturais, políticas, familiares e econômicas ensejaram uma verdadeira evolução legislativa em direção a considerar a existência humana como centro 
de todo o ordenamento jurídico. O ápice do referido processo evolutivo ocorreu com a promulgação do texto constitucional de 1988, seguida da edição do Código Civil de 2002.

A própria Maria Berenice Dias (2007, p.33-34) leciona que o sistema normativo brasileiro elegeu a dignidade humana como o seu valor máximo, trazendo a ideia da função social da propriedade. Desta forma, verifica-se o fenômeno da "repersonalização do direito ou seja, o respeito à pessoa humana coloca o patrimônio e o próprio direito a serviço das pessoas, razão de ser e fim derradeiro de todos os saberes". Assim, "as situações patrimoniais devem ser funcionalizadas em favor das situações existenciais" (GAMA, 2007, p.193).

Neste contexto, também o Direito das Sucessões deve conceber a pessoa como alvo central de sua tutela e proteção. Suas normas devem ser funcionalizadas a partir da afirmação da dignidade humana (DIAS, 2013, p.34). Isto significa que todos os institutos sucessórios inclusive as hipóteses de falta de legitimação para suceder - só têm aplicação enquanto guardarem conformidade com os direitos fundamentais previstos na Constituição.

Pablo Stolze Gagliano e Rodolfo Pamplona Filho (2015, p.50-51) defendem que, como a dignidade da pessoa humana é o filtro necessário para a interpretação de todo o ordenamento jurídico, "toda e qualquer norma, inclusive no Direito Sucessório, que afrontar esse princípio superior pode ter a sua constitucionalidade questionada”. Os autores aduzem ainda que, da mesma forma, a sucessão mortis causa está visceralmente relacionada à ideia de transmissão da propriedade. Por conseguinte, tendo em vista que a Constituição condiciona o exercício deste direito real à sua função social, "as regras hereditárias, consequentemente, também seguem a mesma diretriz".

Em razão da orientação adotada pelos institutos do Direito Sucessório, “o novo perfil da sucessão testamentária, devidamente constitucionalizada, deve abranger especialmente valores existenciais" (GAMA, 2007, p.198). Consequentemente, como já se mencionou, a interpretação das normas sucessórias deve evitar exageros e injustiças, mitigando a severidade quando isto for necessário (NONATO, 1957, v.II, p.70) de forma a garantir o respeito aos preceitos da Constituição.

A partir de tudo quanto exposto, depreende-se que a pergunta formulada na introdução do presente artigo apenas pode ser respondida levando em consideração os princípios constitucionais envolvidos na solução da questão. 
Conforme amplamente exposto na seção 2, os alimentos são "uma das manifestações do direito à vida, vale dizer, um direito que se destina a tutelar a própria integridade física do indivíduo" (GOMES, 1987, p. 409), independentemente de sua causa jurídica ser a lei, um ato ilícito ou uma declaração de vontade inter vivos ou causa mortis.

Nos alimentos deixados através de uma manifestação solene de última vontade, prevalece o caráter de solidariedade intrínseca a tal disposição testamentária. Rolf Madaleno (2007, p.327) sustenta que é evidente a função assistencial do legado em questão, já que mira exclusivamente a subsistência do legatário, na medida em que "não são concebíveis alimentos sem necessidade".

De fato, a liberalidade causa mortis dotada de caráter alimentar revela que o testador tinha o fim e a causa determinante de livrar o legatário da penúria extrema, assegurando-lhe os meios indispensáveis para a sua sobrevivência (MAXIMILIANO, 1964, p.355). A este respeito, deve ser ressaltado que o ordenamento jurídico deve privilegiar e proteger os atos solidários e de assistência, inclusive como forma de garantir amparo aos necessitados.

Em tal contexto, o intérprete deve agir com cautela e prudência no momento de aplicar uma norma que pode restringir ou obstar a efetividade da obrigação alimentar instituída por testamento. Inclusive, deve-se levar em conta que os alimentos constituem um auxílio vital e, portanto, não são fonte de enriquecimento.

A partir dos fundamentos expostos, conclui-se que negar o benefício dos alimentos a alguém realmente necessitado significa obstar a tal pessoa o exercício do seu direito de viver plenamente, privando-o do acesso à educação, à saúde e, de modo geral, às suas demandas vitais mais básicas.

Por essa razão, constata-se que os impedimentos sucessórios estabelecidos pela lei não podem prevalecer quando a sua manutenção viola o direito fundamental à vida $\mathrm{e} o$ princípio constitucional da dignidade da pessoa humana.

Tal entendimento era sustentado mesmo na doutrina anterior à Constituição de 1988 e ao Código Civil de 2002. Pontes de Miranda (1969, v.LVII, p.207) aduz que, no direito romano, era possível constituir a obrigação alimentar por testamento em favor dos não legitimados a suceder. Posteriormente (1969, v.LVIII, p.40), este doutrinador afirma que o legado de alimentos indiscutivelmente é válido se constituído em benefício de filhos adulterinos.

Ainda se referindo ao regramento do Código Civil de 1916, Carlos Maximiliano (1964, p.527) já assevera que o legado de alimentos deve ser cumprido se o legatário 
necessitar deles, na medida do que for primordial para a sua sobrevivência. Defendendo o mesmo ponto de vista, Washington de Barros Monteiro (1999, p.153) sustenta expressamente que "os casos de proibição legal não podem ser sobrepostos ao direito à vida"1.

Os doutrinadores mais recentes ainda têm adotado posicionamento tímido sobre este tema. Entretanto, notam-se posicionamentos claramente direcionados a sobrelevar o direito à vida, afastando as disposições proibitivas. Este é o entendimento defendido por Carlos Alberto Maluf e Adriana Caldas Maluf (2013, p.378), acompanhados por Luiz Paulo Vieira de Carvalho (2014, p.675).

Ressalte-se que tal posicionamento não desconsidera a importância dos impedimentos sucessórios, cuja previsão legal tem fundamentos graves e relevantes. De fato, é importante assegurar a segurança e a liberdade das disposições testamentárias. Nesse sentido, abusos, fraudes e artifícios que violem a real vontade do testador devem ser coibidos pelo juízo do inventário.

Ocorre que, conforme já mencionado, a obrigação alimentar não é fonte de enriquecimento, mas de assistência aos desamparados. Além disso, reitere-se: atos de solidariedade devem ser privilegiados, preservados e protegidos pelo aplicador da norma. Por outro lado, na medida em que a necessidade do legatário é real, torna-se improvável a configuração de fraude.

Defende-se, então, uma interpretação que privilegie o direito à vida (digna), afastando-se a nulidade de pleno direito do legado de alimentos em favor das pessoas não legitimadas a suceder.

Por outro lado, de forma a se respeitar os fundamentos legais dos impedimentos sucessórios, mantém-se a possibilidade de os interessados ${ }^{2}$ fazerem prova de que tal disposição testamentária é fraudulenta ou nunca efetivamente esteve na solene manifestação de vontade do de cujus. Em tal hipótese extrema, o vínculo jurídico entre testador e legatário seria realmente inválido, desaparecendo qualquer obrigação alimentar.

1 Refutando a mencionada opinião manifestada por Washington de Barros Monteiro, Silvio Rodrigues (1999, p.148) afirma que "tal afirmativa, entretanto, ditada pela bondade de seu grande coração, em meu parecer colide com a lei". 


\section{CONCLUSÃO}

Os impedimentos sucessórios são importantes instrumentos previstos pelo legislador, tendo por objetivo resguardar a verdadeira e livre manifestação de última vontade do testador, bem como guardar o decoro familiar e coibir o concubinato.

O legado de alimentos, por sua vez, é uma disposição testamentária motivada pela caridade e pela solidariedade. Não se trata de deixa que enseja o enriquecimento do beneficiado. Seu principal objetivo é livrar o legatário da penúria e da miséria, configurando dentro do direito privado um elogiável mecanismo de efetividade do direito à vida digna.

O fenômeno da constitucionalização do Direito Civil exige que todos os institutos civilistas sejam analisados sob uma perspectiva que coloque a pessoa humana como centro de proteção do ordenamento jurídico. Neste contexto, não é possível admitir que uma norma infraconstitucional sucessória impeça injustificadamente a efetivação de mecanismos asseguradores dos direitos fundamentais à vida e à dignidade.

Por estas razões, conclui-se que, a princípio, é válido o legado de alimentos instituído em favor das pessoas não legitimadas a suceder. Contudo, não se afasta a possibilidade de os interessados fazerem prova de eventual fraude no testamento, de forma a se resguardar a verdadeira manifestação de última vontade do falecido.

\section{REFERÊNCIAS}

CARVALHO, Luiz Paulo Vieira de. Direito das Sucessões. São Paulo: Atlas, 2014.

DIAS, Maria Berenice. Manual das Sucessões. 3. ed. - São Paulo: Revista dos Tribunais, 2013.

GAGLIANO, Pablo Stolze; PAMPLONA FILHO, Rodolfo. Novo Curso de Direito Civil, Volume 7: Direito das Sucessões. 2. ed. rev. e atual. - São Paulo: Saraiva, 2015.

GAMA, Guilherme Calmon Nogueira da. Capacidade Para Testar, Para Testemunhar E Para Adquirir Por Testamento. In: HIRONAKA, Giselda Maria Fernandes Novaes; PEREIRA, Rodrigo da Cunha (org.). Direito Das Sucessões. Belo Horizonte: Del Rey, 2007.

GOMES, Orlando. Direito de Família. 7. ed. - Rio de Janeiro: Forense, 1987.

2 Interessados são os herdeiros legítimos ou testamentários e os demais legatários; ou, enfim, qualquer pessoa que veja seu benefício sucessório reduzido ou onerado em razão do legado de alimentos. 
GONÇALVES, Carlos Roberto. Direito Civil Brasileiro, volume 6: direito de família. 9. ed. - São Paulo: Saraiva, 2012.

Direito Civil Brasileiro, volume 7: direito das sucessões. 7. ed. - São Paulo:

Saraiva, 2013.

ITABAIANA DE OLIVEIRA, Arthur Vasco. Tratado de Direito das Successões, Vol II . 3. ed. - Rio De Janeiro: Livraria Jacintho, 1936.

LACERDA DE ALMEIDA, Francisco de Paula. Successões. Rio de Janeiro: Revista dos Tribunais, 1915.

MADALENO, Rolf. Legados e Direito de Acrescer entre Herdeiros e Legatários. In:

HIRONAKA, Giselda Maria Fernandes Novaes; PEREIRA, Rodrigo da Cunha (org.). Direito Das Sucessões. Belo Horizonte: Del Rey, 2007.

MALUF, Carlos Alberto Dabus; MALUF, Adriana Caldas do Rego Freitas Dabus. Curso de Direito das Sucessões. São Paulo: Saraiva, 2013.

MAXIMILIANO, Carlos. Direito das Sucessões, volume II. 5. ed. - Rio de Janeiro: Livraria Freitas Bastos, 1964.

MONTEIRO, Washington de Barros. Curso de Direito Civil, v.6 - São Paulo: Saraiva, 1999.

NONATO, Orosimbo. Estudos sobre Sucessão Testamentária, volume II. Rio de Janeiro: Revista Forense, 1957.

Forense, 1957.

Estudos sobre Sucessão Testamentária, volume III. Rio de Janeiro: Revista

PEREIRA, Caio Mário da Silva. Instituições de direito civil, v.6: Direito das Sucessões. 20. ed. - Rio de Janeiro: Forense, 2013.

PONTES DE MIRANDA, Francisco Cavalcanti. Tratado de Direito Privado: parte especial, Tomo LV. Rio de Janeiro: Borsoi, 1968.

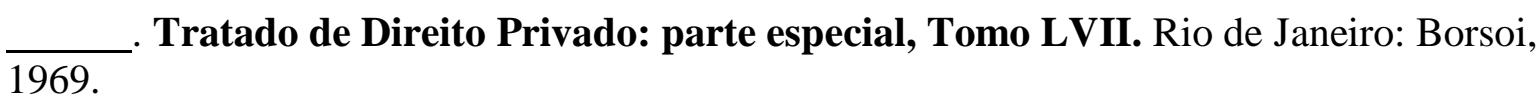

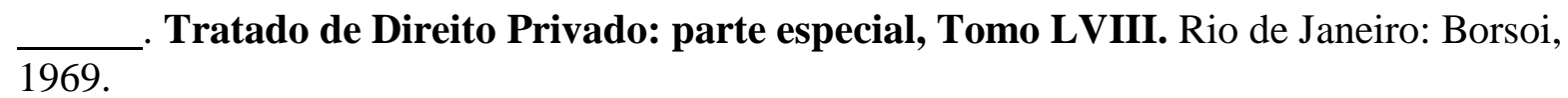

RODRIGUES, Silvio. Direito Civil, V. 7. 23. ed. rev. - São Paulo: Saraiva, 1999.

WALD, Arnoldo. Direito de Família. 8. ed. - São Paulo: Revista dos Tribunais, 1991. 